\title{
Analysis of the Performance and Overall Efficiency of a Formula Student Electric Car
}

\author{
Leone Martellucci, Marco Giannini \\ Department of Astronautical, Electrical and Energy Engineering, Sapienza University, Rome, Italy \\ Email: leone.martellucci@uniroma1.it,mk.giannini96@gmail.com
}

How to cite this paper: Martellucci, L. and Giannini, M. (2022) Analysis of the Performance and Overall Efficiency of a Formula Student Electric Car. Journal of Transportation Technologies, 12, 111-122. https://doi.org/10.4236/jtts.2022.121007

Received: December 31, 2021

Accepted: January 25, 2022

Published: January 28, 2022

Copyright $\odot 2022$ by author(s) and Scientific Research Publishing Inc. This work is licensed under the Creative Commons Attribution International License (CC BY 4.0).

http://creativecommons.org/licenses/by/4.0/ (c) (i) Open Access

\begin{abstract}
In this paper, the performance and overall efficiency optimization process for a full-electric Formula Student car are reported. The Formula Student Electric is a scientific-educational competition of high technological value that requires the development and construction of a fully electric open-wheel prototype car; the cars rival both in terms of absolute performance and in terms of total energy efficiency, especially in the most important test, the endurance event. The optimization of the performance and efficiency of the cars affects various aspects of both the powertrain and the car body and, as macro areas, three crucial themes can be identified for the development of the cars: the power maps with which the inverter manages the electric motor, the aerodynamic kit installed onboard and the overall weight of the car. In this regard, in fact, it is not obvious, for example, that it is convenient to use the maximum power allowed by the rules for the powertrain $(80 \mathrm{~kW})$; in the same way, it is not inevitable that it is advantageous to install all the components of the aerodynamic kit (front wing, rear wing and undertray with diffusers) and, finally, the best configuration may not be the one with the lightest car. This is also in consideration of the fact that some choices must necessarily be a compromise, such as completeness of the aerodynamic kit and vehicle weight. Hence the search for an optimum point is necessary. The work proposed here aims to describe the experimental search for the optimal configuration for the car of the Sapienza Fast Charge team. To achieve the goal, the analysis has been conducted with several experimental tests on a simple test ring with a dynamic configuration comparable to that of a typical endurance track. The tests have been fulfilled with different combinations of aero-kit configurations, with the aero devices available on the car, rear wing, front wing and undertray, and with different energy management strategies, implemented in the power map of the inverter. The best result has been achieved considering the official ranking calculation of the Formula Student rules 2020, with a combination of best track time and lower energy consumption. The work de-
\end{abstract}


scribed here will start with the description of the prototype vehicle, reporting the details of the powertrain and storage system installed onboard. Then, the aerodynamic devices designed and built will be described, and the CFD analysis of their performances will also be reported. In the following, the description of the test track will be discussed and a comparison of a typical track of an Endurance test in Formula Student will be fulfilled. Finally, the parameters measured experimentally will be described and all the tests carried out will be discussed, in order to determine the optimal configuration of the car.

\section{Keywords}

Vehicle, Electric, Aerodynamic, Energy, Experimental

\section{Vehicle Description}

The car covered by this paper responds entirely to the dictates of the Formula Student rules, both as SAE (society of automotive engineers) and FSG (Formula student Germany). Formula student is an international championship where universities students test themselves designing and building three different categories of a single seater race car: Electric, internal combustion and autonomous-driving cars. The rules give the main guidelines to fulfill to guarantee, overall, safety of drivers and stewards. Formula Student competitions are constituted by statics engineering events and track tests. The track tests give the main part of all competition's points and the most important is the endurance test: a race of 22 $\mathrm{km}$ on a very technical track characterized by frequent acceleration and braking.

The car considered in this paper (Figure 1) is from "Sapienza Fast Charge" team and presents the following characteristics. The rolling chassis is a steel tubes space frame structure with A-arms and push rod suspensions; hubs and uprights in ergal aluminum alloy, with magnesium alloy wheel with Pirelli slick tires. The complete vehicle weighs, without the driver on board, $240 \mathrm{~kg}$, the battery pack alone weighs $54 \mathrm{~kg}$, and the motor and inverter weigh $20 \mathrm{~kg}$. The overall weight distribution is 50:50 considering a $75 \mathrm{~kg}$ driver and the aerodynamic kit that is composed of the front wing, rear wing and undertray with diffuser. The car is equipped with $6.3 \mathrm{kWh}$ energy storage (Figure 2) in 90s3p configuration using li-po pouch cells, with $380 \mathrm{~V}$ of maximum voltage and capable of 150 A of burst charge current, to be considered in the regenerative braking system design. Energy storage's container is built by carbon and kevlar fiber to enhance the power-to-weight ratio and guarantee excellent electric-insulation, flame resistance and mechanical proprieties.

Electronics and safety systems are partially commercial and partially from Team's design: The Vehicle Control Unit, specific for automotive applications, is programmable with MATLAB-Simulink and the Battery Management System (BMS) is commercial but with firmware modified by the team. The BMS allows to monitor and log temperatures and voltage of each cell parallel, to collect large 


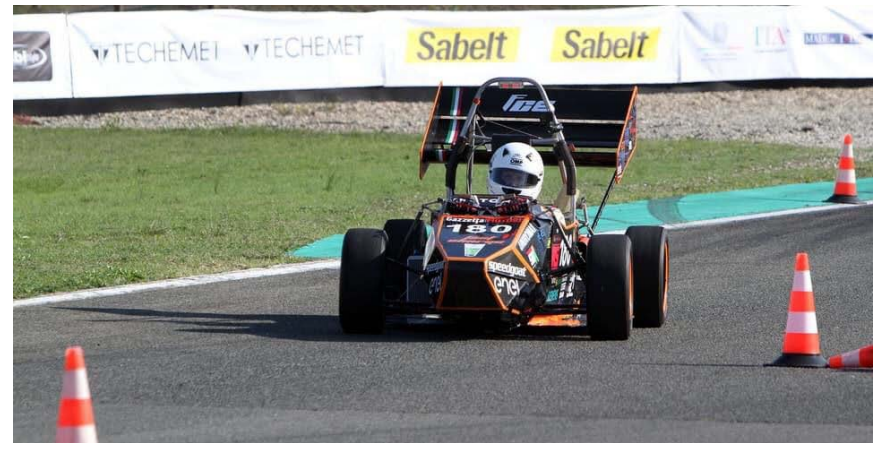

Figure 1. The formula student car (courtesy by Sapienza fast charge team).
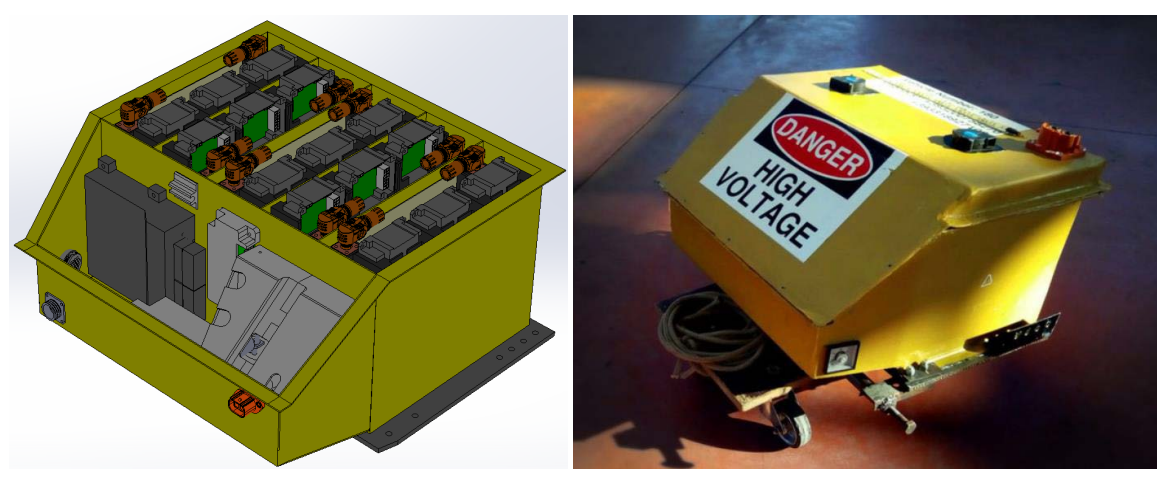

Figure 2. The storage system (courtesy by Sapienza fast charge team).

amount of experimental data; it is useful for regenerative braking, because burst charge during regenerative braking is thermally stressful for the li-po cells. The full electric powertrain is made up of a permanent magnet axial flux motor that delivers $100 \mathrm{~kW}$ and $240 \mathrm{Nm}$; it is connected to the wheels with a chain transmission with 11/45 pinion/crown ratio and an adjustable Limited Slip Differential. The electric drive is managed by a $450 \mathrm{~V}$ electronic inverter with canbus line communication with Vehicle Control Unit and data logging system. As already explained, main target of this case study is to set the best configuration of the regenerative braking device to maximize the total recovered energy during braking phase (without rear wheels locking) in a typical Formula Student Endurance Event. As a result of this work, the expected recovered energy during the Endurance Event will be evaluated considering all the system constrains [1]; it will be very important information to design the new storage system for Season 2021 car. In order to develop the project of a Formula Student energy storage system, several kinds of information are needed but the most important one is the energy required to complete the endurance event. It is needed to choose the right configuration of cells in series and parallel to comply with battery pack voltage (nominal and maximum) in the best matching possible with inverter voltage range [2].

\section{Aerodynamic Kit Specifications}

The aerodynamic kit is composed of three main devices, the front wing, the rear wing and the undertray with diffuser, as reported in Figure 3. 

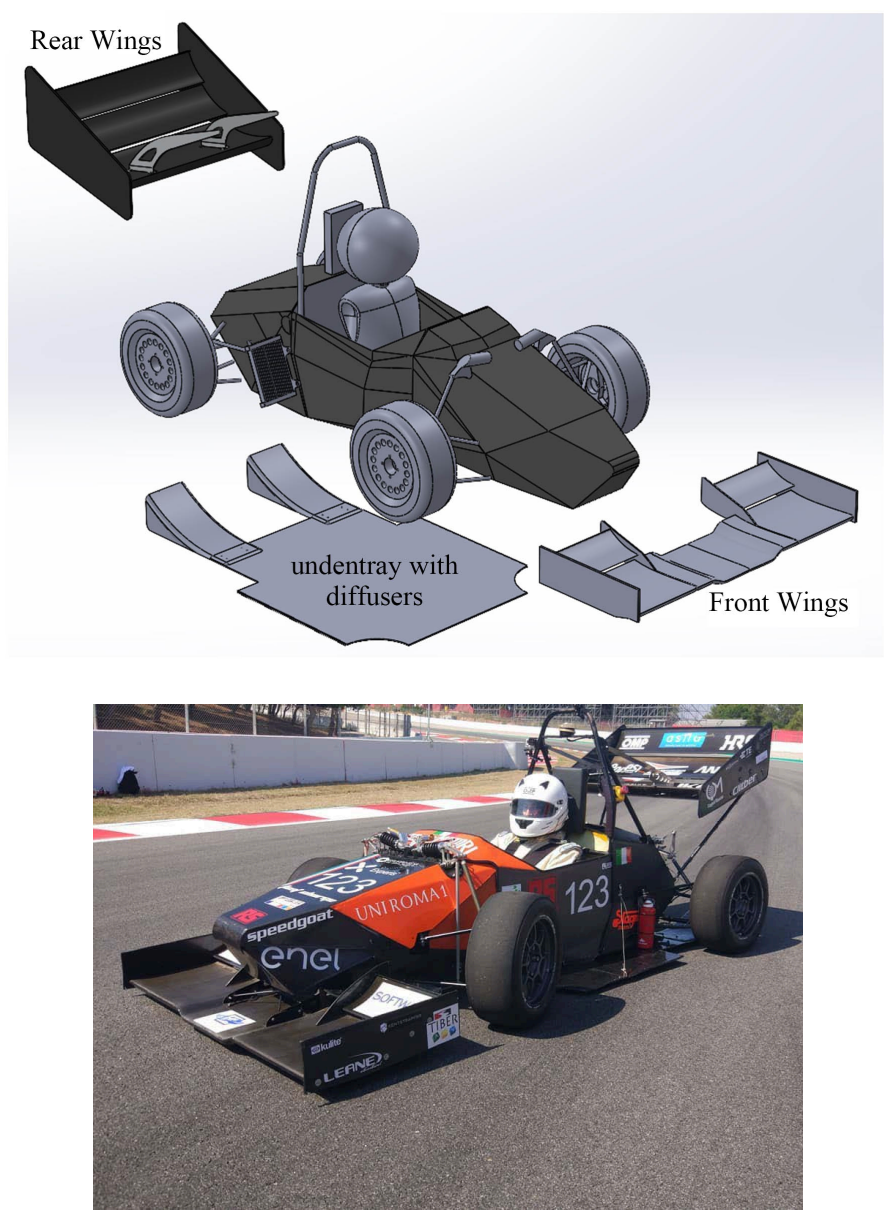

Figure 3. Aerodynamic kit components (courtesy by Sapienza fast charge team).

The front wing is composed of the main wing and two flaps, linked together by two vertical walls for each flap. The external one is the endplates. The profile of these wings and flaps is a custom profile, designed in house by the team to optimize the performances. It is built in carbon fiber and the overall weight is 3.8 $\mathrm{kg}$, including $0.59 \mathrm{~kg}$ of steel mounting supports. The rear wing is composed by the main wing and two smaller wings, linked together by two vertical endplates.

The wings profile is the same as front wings. The overall weight is $3.36 \mathrm{~kg}$, including $0.53 \mathrm{~kg}$ of lightweight aluminum alloy and carbon fiber supports. The undertray is composed of the two flow extractors and the main plate-side, placed under the car. This component is fundamental to achieve a lower drag coefficient of the car because the bottom surface of the car is very irregular and not optimized with air flow paths. The profile of extractors is designed in house by the team to optimize the performances and the overall weight is $5 \mathrm{~kg}, 2 \mathrm{~kg}$ for the extractors and $3 \mathrm{~kg}$ for the main plate. The wings profile has been analyzed and optimized with CFD calculation. Resulting from these CFD calculations, front wings, rear wings and undertray can provide down force and drag resistance as reported in Figure 4 and Figure 5. 


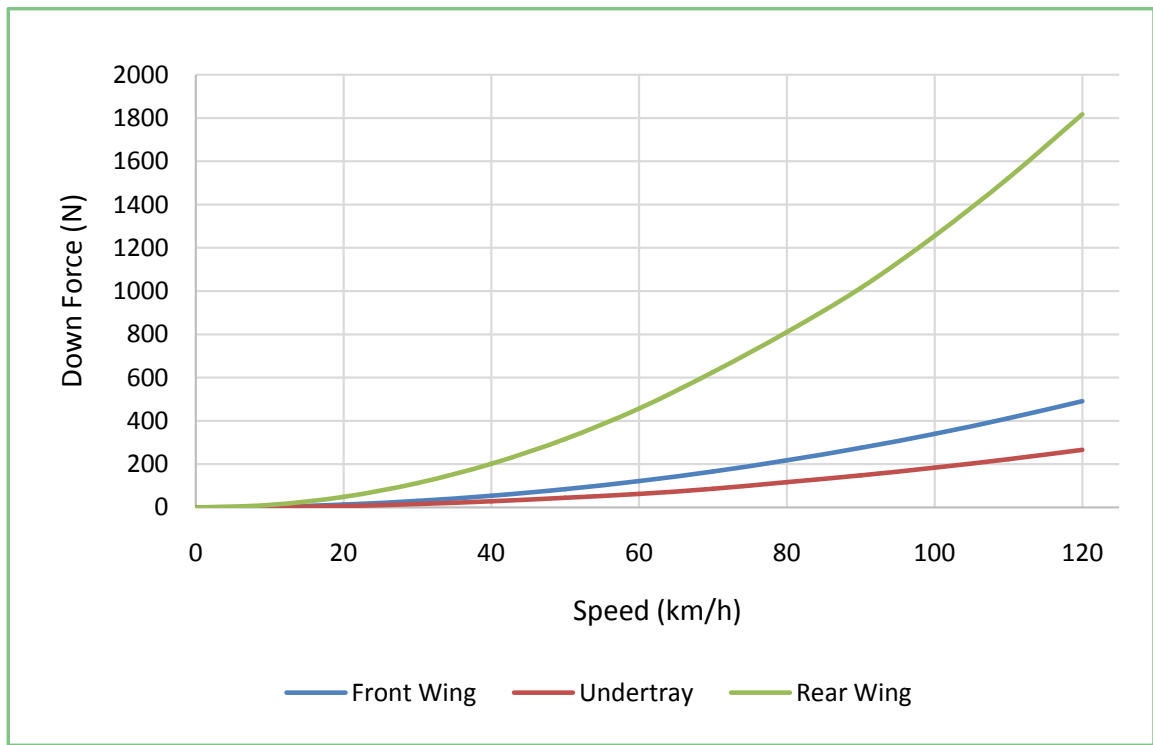

Figure 4. Down forces vs vehicle speed (CFD results, courtesy by fast charge team).

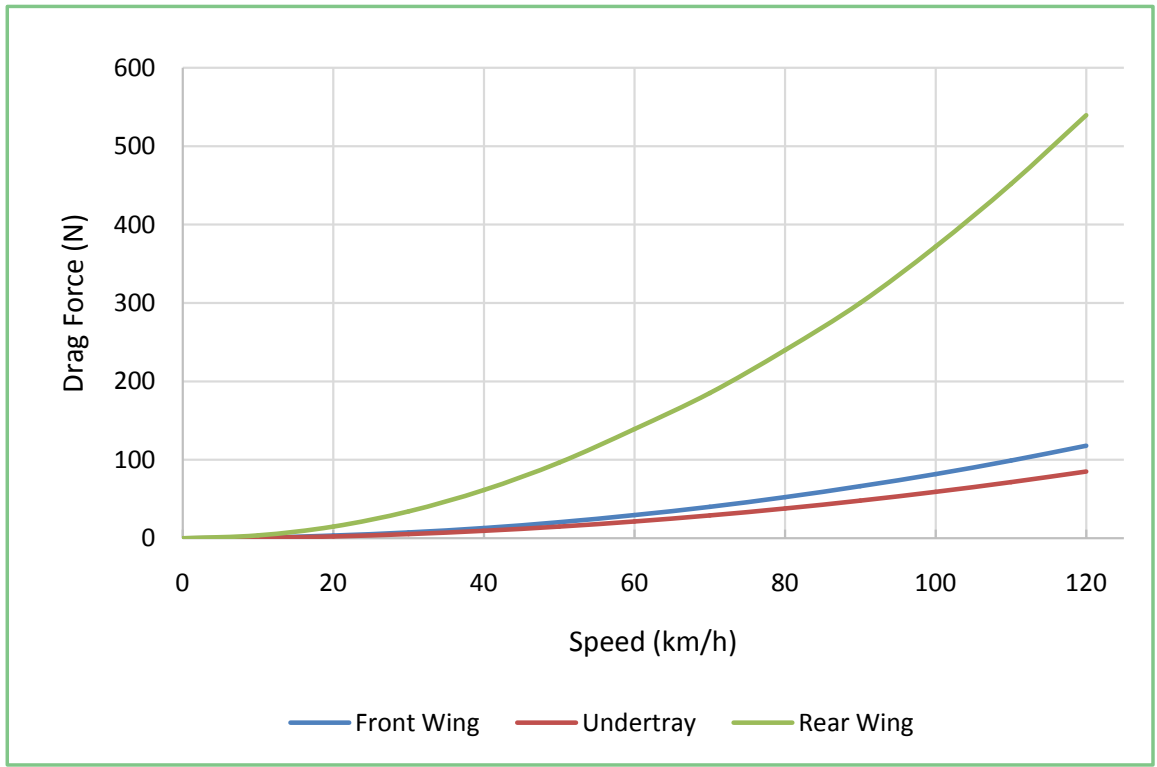

Figure 5. Drag forces vs vehicle speed (CFD results, courtesy by fast charge team).

\section{Experimental Test Planning}

As mentioned, the goal of this work is to study and optimize the performance and energy consumption of the Formula Student car of the Sapienza Fast Charge team during the endurance event; this event is the most relevant within the Formula Student competitions and is generally characterized as a round on track $800 \mathrm{~m}-1000 \mathrm{~m}$ long, which must be covered consecutively for a total of $22 \mathrm{~km}$ at the maximum possible speed and with the lowest possible energy consumption. There are numerous parameters to be optimized on the vehicle to best perform this type of test; in the work carried out here, attention was focused on the aerodynamic configuration of the car and on the power map set on the inverter. 
Experimental tests were then carried out on the track, in order to highlight the optimal configuration for the endurance event for speed performance and energy consumption.

In Figure 6 a typical endurance event track is reported; the experimental tests here reported and discussed were carried out on a simplified and easily repeatable course that reproduces the straights and curves typical of an official endurance event.

The maximum straight for an endurance track is $80 \mathrm{~m}$ and the corners must have a diameter between $9 \mathrm{~m}$ and $18 \mathrm{~m}$. For this test, the track is composed of two curves with diameter of $9 \mathrm{~m}$ and $15 \mathrm{~m}$ and two straight of $80 \mathrm{~m}$, compliant with the rules.

The track, as described and shown in Figure 7, is $215 \mathrm{~m}$ in length and it is $3 \mathrm{~m}$ in width.

For the tests, the car runs ten laps for a total of $2.15 \mathrm{~km}$ length run. At the end of fifth lap the car run on the blue straight to change the sense of track to have an optimal tires consumption and run the same curve in both driving sense.

The start line is the green line, at the beginning of the straight (running in anticlockwise for the bigger curve) and the finish line is at the end of the bigger curve in clockwise sense.

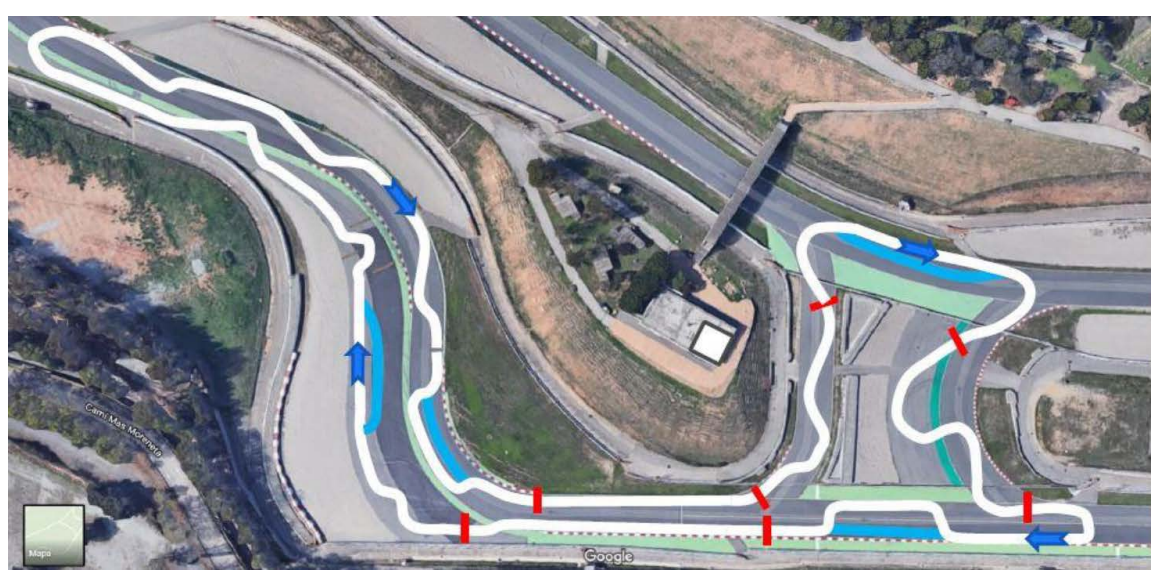

Figure 6. Example of official endurance event (formula student spain 2020).

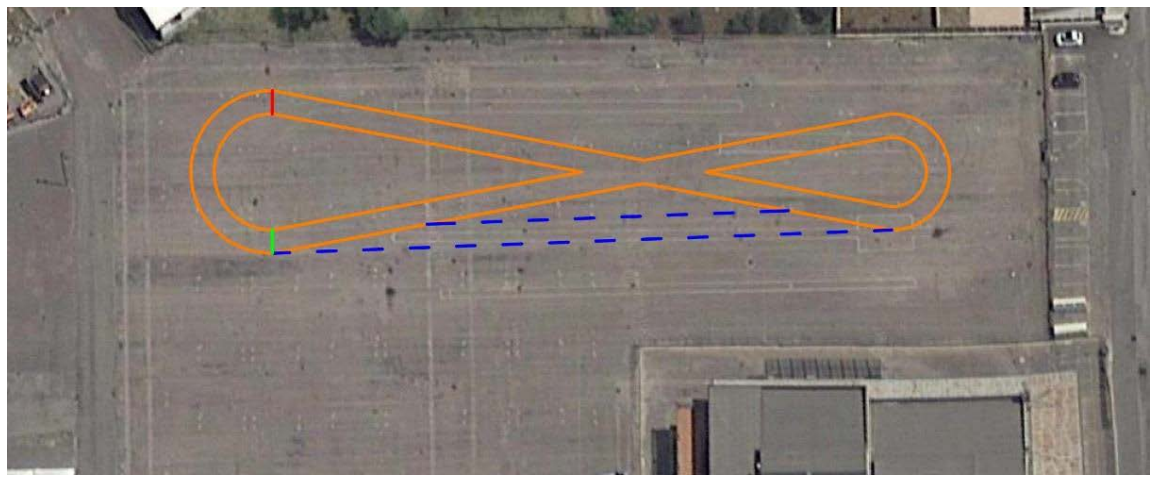

Figure 7. Simplified endurance-type track. 
To compare the results with a real endurance race, the data have been scaled in a $22 \mathrm{~km}$ run.

The analysis carried out is mainly energy, so the aerodynamic aspects have not been analyzed in specific detail, but the differences from a performance and mileage consumption point of view have been evaluated by also considering the driver responses on driving ease.

Each test was measured to obtain a comparison also on performance and calculate the score that would have been obtained in the Endurance race; in fact, this is calculated on the basis of both the time taken and the energy used, with the official score formulas reported on Formula Student rules 2020.

Three different configurations of the aerodynamic kit have been considered; in the first configuration only the undertray is installed on the car, the second configuration is made up of the undertray and the rear wing and the third configuration has with all aero devices installed onboard.

Concerning the power configurations of the electronic inverter, four different power configurations have been considered for each aero configuration.

The power configuration is obtained by limiting the inverter controller maximum current deployed to the motor.

The current limits considered are $125 \mathrm{~A}, 175 \mathrm{~A}, 200 \mathrm{~A}, 250 \mathrm{~A}$. To avoid thermal issues [3] [4] that would have affected the tests, regenerative braking has been disabled. Its optimization was the subject of previous work [5]. All the tests were performed with the same tires pressure (measured with cold tires), the same dynamic configuration and the energy storage voltage ( $4 \mathrm{~V}$ for each cell) and temperature (ambient temperature).

For this study the datalogger stores data at $20 \mathrm{hz}$ frequency, and the following parameters have been considered for the analysis:

- DC current between Energy Storage System and motor controller.

- Total Energy Storage System voltage (DC Voltage).

- Motor RPM.

In Figures 8-10, an example of logs of DC current, DC Voltage and DC Power are reported, for the test of the configuration with only the rear wings installed and current limit of $250 \mathrm{~A}$ on the motor side of electronic inverter.

\section{Experimental Test Results}

For each aero configuration, four different current settings were tested. In Table 1 , all test results are reported. The results obtained in the experimental tests are interesting and allows to extract useful considerations for the optimization of the car; in fact, first of all, there was a significant improvement in the handling of the car with the addition of aerodynamic devices, which made it possible to run the circuit with greater ease for the driver. In general, as expected, the performance of the tests showed that a greater available power leads to a decrease in the travel time of the track and an increase in mileage consumption. However, this aspect is not confirmed if the aerodynamic configurations are compared, in 
fact in the passage from the configuration with the rear wing to the complete one, with also the front wing, the times have slightly worsened; while passing from the configuration with only the undertray to the one with undertray and rear wing, the improvement is evident, both from a time and consumption point of view [6] [7].

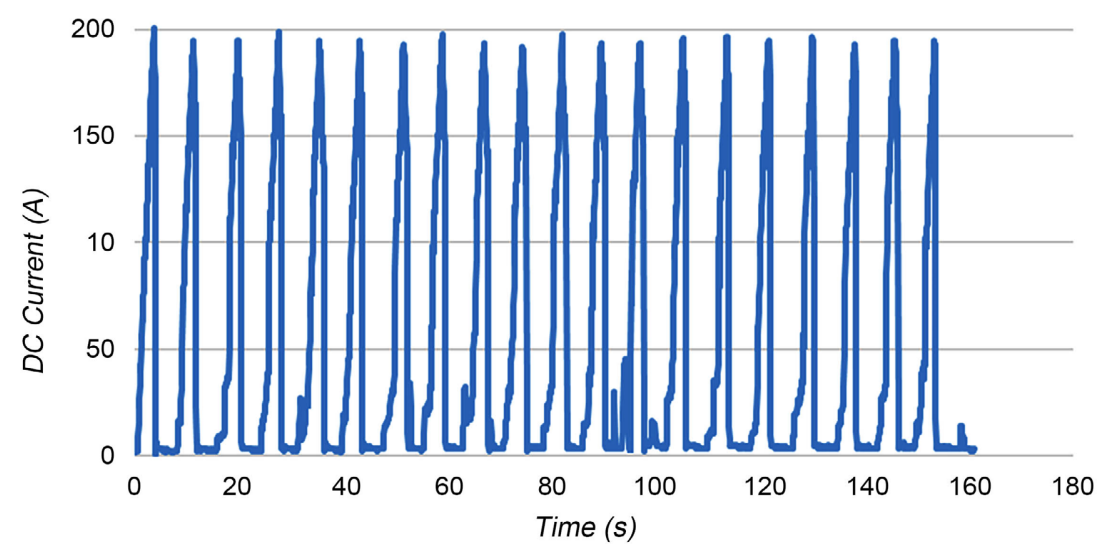

Figure 8. DC current log for test with rear wings and current limitation of $250 \mathrm{~A}$.

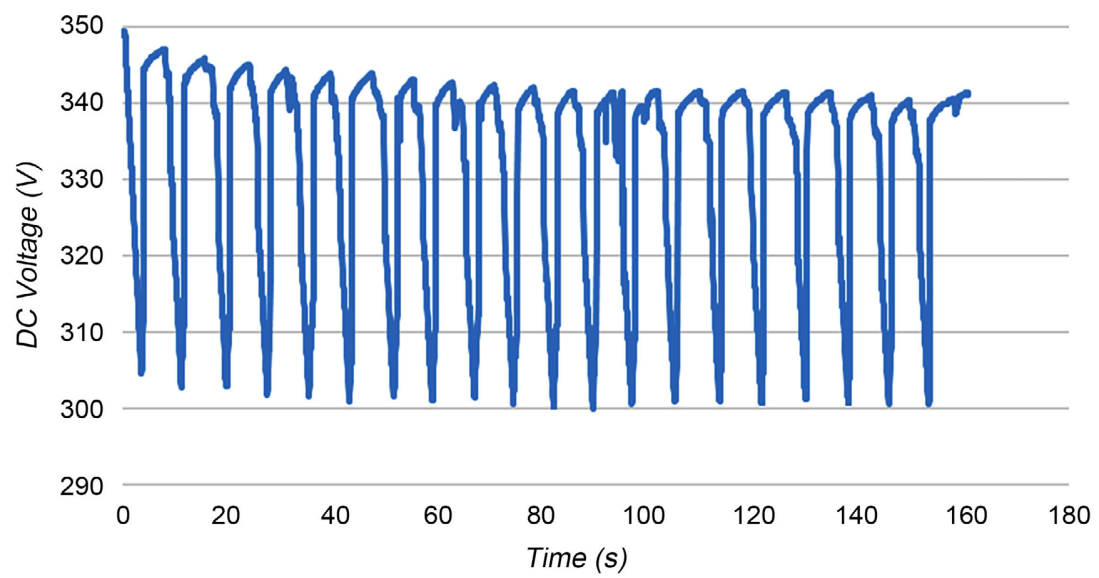

Figure 9. DC voltage log for test with rear wings and current limitation of $250 \mathrm{~A}$.

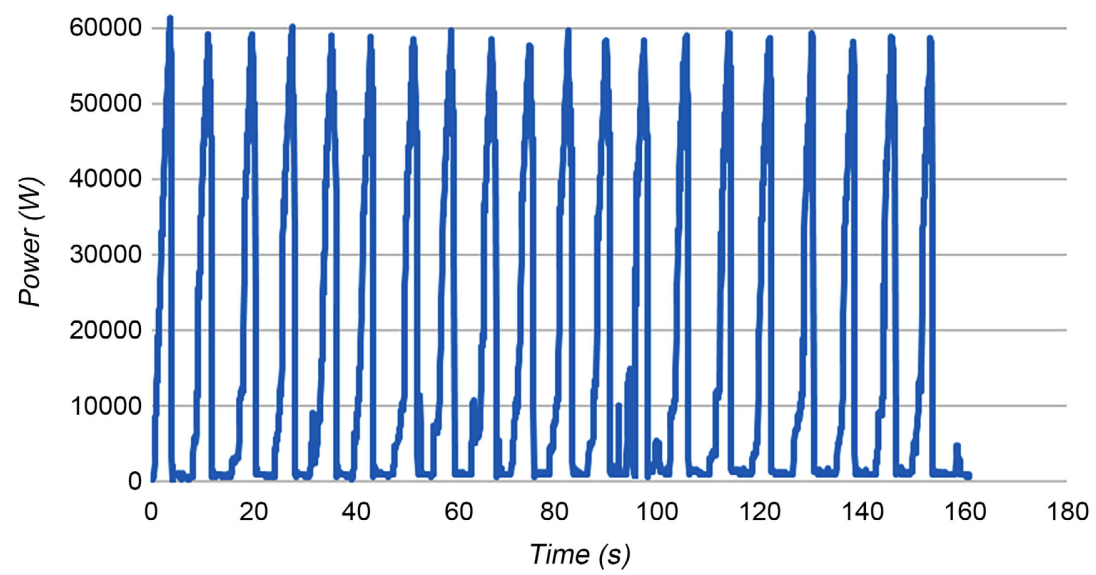

Figure 10. Output power from battery pack with rear wings, current limitation $250 \mathrm{~A}$. 
Table 1. Overall raw test results.

\begin{tabular}{|c|c|c|c|c|c|c|c|c|c|c|c|c|}
\hline \multirow[b]{2}{*}{ Max. Inverter Current [A] } & \multicolumn{4}{|c|}{ Undertray } & \multicolumn{4}{|c|}{ Post } & \multicolumn{4}{|c|}{ Full kit } \\
\hline & 125 & 175 & 200 & 250 & 125 & 175 & 200 & 250 & 125 & 175 & 200 & 250 \\
\hline Run length [m] & 2169 & 2155 & 2101 & 2183 & 2159 & 2169 & 2190 & 2195 & 2165 & 2184 & 2183 & 2185 \\
\hline Time 10 laps [s] & 177.59 & 169.53 & 175.19 & 167.79 & 179.23 & 166.01 & 166.48 & 159.15 & 181.15 & 169.99 & 169.53 & 161.47 \\
\hline Time endurance $[\mathrm{s}]$ & 1801.28 & 1731.05 & 1834.08 & 1690.73 & 1825.95 & 1684.09 & 1672.05 & 1595.33 & 1840.61 & 1712.19 & 1708.7 & 1625.43 \\
\hline Energy 10 lap [Wh] & 439.3 & 491.5 & 538.6 & 568.8 & 409.9 & 568.3 & 537.9 & 639.5 & 515.2 & 542 & 475.8 & 586 \\
\hline Energy/km [Wh] & 202.5 & 228.1 & 256.3 & 260.5 & 189.8 & 262 & 245.6 & 291.4 & 237.9 & 248.1 & 218 & 268.1 \\
\hline Energy endurance [Wh] & 4455.4 & 5018.7 & 5639.4 & 5731.1 & 4176.4 & 5764.9 & 5402.8 & 6410.4 & 5234.3 & 5458.9 & 4795.4 & 5899.2 \\
\hline Max current $[\mathrm{A}]$ & 96 & 142 & 168 & 203 & 91 & 150 & 169 & 201 & 93 & 144 & 161 & 199 \\
\hline Max power [W] & 31,363 & 47,329 & 53,407 & 63,783 & 29,930 & 47,250 & 51,748 & 61,325 & 32,169 & 48,830 & 51,391 & 62,227 \\
\hline Max speed $[\mathrm{km} / \mathrm{h}]$ & 74.9 & 87.5 & 83.7 & 88.1 & 72.1 & 84.4 & 82 & 87.7 & 73.8 & 83 & 80.6 & 96 \\
\hline Lap $1[\mathrm{~s}]$ & 18.97 & 18.61 & 19.36 & 18.49 & 19.47 & 18.31 & 16.35 & 16.79 & 19.17 & 18.91 & 17.58 & 17.85 \\
\hline Lap $2[\mathrm{~s}]$ & 17.78 & 16.50 & 18.69 & 17.35 & 17.84 & 17.25 & 15.64 & 15.75 & 17.61 & 16.72 & 17.13 & 16.16 \\
\hline Lap 3 [s] & 17.99 & 16.50 & 17.33 & 16.12 & 18.22 & 16.71 & 16.87 & 15.87 & 17.91 & 17.68 & 15.76 & 15.64 \\
\hline Lap $4[\mathrm{~s}]$ & 17.61 & 17.51 & 17.91 & 16.26 & 17.99 & 17.18 & 17.07 & 15.57 & 17.53 & 16.63 & 16.67 & 15.8 \\
\hline Lap $5[\mathrm{~s}]$ & 17.25 & 16.89 & 17.63 & 15.85 & 17.18 & 16.49 & 16.46 & 15.22 & 18.35 & 16.19 & 16.19 & 15.36 \\
\hline Lap $6[\mathrm{~s}]$ & 17.47 & 16.30 & 17.09 & 15.35 & 17.73 & 16.02 & 15.96 & 14.81 & 18.44 & 15.6 & 16.81 & 15.9 \\
\hline Lap 7 [s] & 17.77 & 16.88 & 16.23 & 15.70 & 17.54 & 15.69 & 16.99 & 16.8 & 17.94 & 16.2 & 17.37 & 15.86 \\
\hline Lap 8 [s] & 17.30 & 17.00 & 17.13 & 15.42 & 18.15 & 16.41 & 17.08 & 16.34 & 17.16 & 17.28 & 17.84 & 16.37 \\
\hline Lap $9[\mathrm{~s}]$ & 17.80 & 16.89 & 16.73 & 19.70 & 17.74 & 16.12 & 17.14 & 15.9 & 17.81 & 17.22 & 17.39 & 16.59 \\
\hline Lap 10 [s] & 17.65 & 16.45 & 17.09 & 17.55 & 17.37 & 15.83 & 16.92 & 16.1 & 19.23 & 17.56 & 16.79 & 15.94 \\
\hline Total time $[\mathrm{s}]$ & 177.59 & 169.53 & 175.19 & 167.79 & 179.23 & 166.01 & 166.48 & 159.15 & 181.15 & 169.99 & 169.53 & 161.47 \\
\hline
\end{tabular}

Endurance estim. time [s] $1801.28 \quad 1731.05 \quad 1834.08 \quad 1690.73 \quad 1825.95 \quad 1684.091672 .051595 .33 \quad 1840.611712 .191708 .7 \quad 1625.43$

This apparent inconsistency in the tests with both wings installed can be explained by the fact that in this kind of tracks, with short straights, the influence of the front wing is reduced, while the mass of the wing itself increases the weight of the vehicle by about $5 \%$, effectively leading to worst performance. The question of weight is very important in a car that weighs just over $200 \mathrm{~kg}$.

In order to extrapolate a projection of the experimental data and compare them with a real endurance event in Formula Student, using the formulas reported in the official Formula Student 2020 rules, and based on the real results of the Formula Student Germany 2020 event, the scores that the Sapienza Fast Charge car would have obtained in terms of performance and energy efficiency were calculated for each configuration considered. In Table 2, these calculations are reported. 
Table 2. Endurane event scores estimation.

\begin{tabular}{cccccc}
\hline Configuration & $\begin{array}{c}\text { Endurance Time } \\
T_{\text {team }}\end{array}$ & $\begin{array}{c}\text { Endurance } \\
\text { Score }\end{array}$ & $\begin{array}{c}\text { Endurance Energy } \\
E_{\text {team }}(\text { Wh })\end{array}$ & $\begin{array}{c}\text { Efficiency } \\
\text { Score }\end{array}$ & $\begin{array}{c}\text { Total } \\
\text { Score }\end{array}$ \\
\hline Post 250 & 1595.33 & 118.61 & 6410.4 & 85.95 & 204.56 \\
Full 250 & 1625.43 & 100.19 & 5899.2 & 89.84 & 190.03 \\
Post 200 & 1672.05 & 72.97 & 5402.8 & 93.19 & 166.16 \\
Post 175 & 1684.09 & 66.19 & 5764.9 & 90.1 & 156.29 \\
Undertray 250 & 1690.73 & 62.49 & 5731.1 & 90.29 & 152.78 \\
Full 200 & 1708.7 & 52.62 & 4795.4 & 97.3 & 149.92 \\
Full 175 & 1712.19 & 50.73 & 5458.9 & 92.24 & 142.97 \\
Undertray 175 & 1731.05 & 40.64 & 5018.7 & 95.44 & 136.08 \\
Undertray 125 & 1801.28 & 25 & 4455.4 & 0 & 25 \\
Post 125 & 1825.95 & 25 & 4176.4 & 5639.4 & 0 \\
Undertray 200 & 1834.08 & 25 & 5234.3 & 0 & 25 \\
Full 125 & 1840.61 & 25 & & 0 & 25 \\
\hline
\end{tabular}

By observing the results calculated in Table 2, it can be seen how the score rewards pure performance more than efficiency. For this reason, the configuration with undertray and rear wing with a current limit of $250 \mathrm{~A}$ prevailed, with which the track was covered in the shortest time, despite being the configuration with the highest energy consumption.

Comparing this better result with those of the Formula Student Germany 2020 classification, the Sapienza Fast Charge car would have placed sixth in the Endurance classification and eighth in the Efficiency classification.

By adopting, instead, the configuration with the lowest mileage consumption, among those that would have obtained points in the Efficiency classification, that is the one with all the complete aerodynamic kit and current limitation at $175 \mathrm{~A}$, the car would have achieved a better placement in the Efficiency classification, but it would be heavily penalized in the Endurance classification, obtaining a total of around 70 points less.

The EnduranceTime and Endurance Energy data are obtained, as mentioned in the previous paragraph, by scaling the values measured with the 10 laps (about $2.2 \mathrm{~km}$ ) of tests carried out for each of the analyzed configurations over $22 \mathrm{~km}$, the length of an endurance event in Formula Student.

The values relating to the hypothetical scores shown in Table 2 are calculated based on the classification of the endurance event of Formula Student Germany 2020 and using the formulas for the calculation of the scores reported in Formula Student Rules 2020 and summarized here for convenience:

$$
\text { Endurance Score }=300\left(\frac{\left(\left(\frac{T_{\max }}{T_{\text {team }}}\right)-1\right)}{0.333}\right)
$$




$$
\begin{aligned}
& \text { Efficiency Score }=100\left(\frac{\left(\left(\frac{0.1}{E_{\text {team }}}\right)-1\right)}{\left(\frac{0.1}{E_{\text {max }}}\right)-1}\right) \\
& \text { Efficiency Factor }=\left(\frac{T_{\min } * E N_{\text {min }}^{2}}{T_{\text {team }} * E N_{\text {team }}^{2}}\right)
\end{aligned}
$$

where:

- $T_{\max } \mathrm{x}$ is 1.333 times of the elapsed time of the fastest vehicle.

- $T_{\text {team }}$ is the team's elapsed driving time.

- $T_{\min }$ is the fastest elapsed driving time of all teams who are able to score points in efficiency.

- $E_{\text {team }}$ is the team's efficiency factor.

- $E_{\max }$ is the highest efficiency factor of all teams who are able to score points in efficiency.

- $E N_{\text {team }}$ is the team's used energy.

- $E N_{\min }$ is the lowest used energy of all teams who are able to score points in efficiency.

In Formula Student Germany 2020, the following values are obtained:

$$
T_{\operatorname{mim}}=1321.5 \mathrm{~s}, T_{\max }=1761.09 \mathrm{~s}, E N_{\min }=4474 \mathrm{Wh} \text { and } E_{\max }=0.80 .
$$

\section{Conclusion}

The experimental tests were carried out to provide data that estimate real consumption, extrapolating the data on a track of 22 full $\mathrm{km}$. The study made it possible to experimentally highlight the lack of effectiveness of the front wing which, in consideration of the limited extension of the straights in the Formula Student events, fails to produce downforce that justifies the weight of the device. The results analyzed here, therefore, suggest using the rear wing and the undertray device, which allow a significant improvement in the car's performance and ease of driving. The study and experimental analysis also made it possible to explore the topic of energy consumption expected during an endurance event for the Sapienza Fast Charge car. From the data collected in the tests, it was in fact observed that the most effective configuration has an energy consumption at the limit of the current battery pack, with estimated energy consumption for Endurance of approximately $6.4 \mathrm{kWh}$ considering the use of regenerative braking. However, if it were not possible to take advantage of the regenerative braking for thermal reasons, the consumption would rise to about $7.1 \mathrm{kWh}$, while the energy of the pack, influenced by various factors, such as the balance and deterioration of the cells, the temperature, and the discharge current, is between the nominal value of $6.3 \mathrm{kWh}$ and the maximum value of $7.1 \mathrm{kWh}$. So, there would be little safety margin, which is always necessary to have, to avoid unfavorable conditions leading to exhaustion of the charge before the finish of the race. During the design of the new battery pack, it was therefore decided to increase the available 
energy, using a $7 \mathrm{p} 108$ s configuration with 18,650 cylindrical cells, which allows reaching the $450 \mathrm{~V}$ maximum voltage (inverter limit). In the chosen configuration, the battery pack would have nominal energy of $7.9 \mathrm{kWh}$ and a maximum of $9.2 \mathrm{kWh}$, obtaining a good safety margin to fully exploit the potential of the traction system. With the new battery pack, it will be possible to obtain new important data on the real consumption of the car, in a complete Endurance course and confirm or correct the results obtained in the tests described and discussed here.

\section{Acknowledgements}

Thanks to POMOS, Center for Sustainable Mobility of Sapienza University of Rome, for the infrastructures available for the experimental activity. Thanks to Damiano Romanese for his support in the construction and experimental tasks.

\section{Conflicts of Interest}

The authors declare no conflicts of interest regarding the publication of this paper.

\section{References}

[1] Wei, Y.Y., Lin, Y., Lin, C., Wang, Z.P. and He, H.W. (2005) The Study on ChargeDischarge Characteristics and Application of Li-Ion Battery for Vehicle. Vehicle \& Power Technology, 28-31.

[2] Emadi, A., Lee, Y.J. and Rajashekara, K. (2008) Power Electronics and Motor Drives in Electric, Hybrid Electric, and Plug-In Hybrid Electric Vehicles. IEEE Transactions on Industrial Electronics, 55, 2237-2245. https://doi.org/10.1109/TIE.2008.922768

[3] Xia, G., Cao, L. and Bi, G. (2017) A Review on Battery Thermal Management in Electric Vehicle Application. Journal of Power Sources, 367, 90-105. https://doi.org/10.1016/j.jpowsour.2017.09.046

[4] Liu, G.M., Ouyang, M.G., Lu, L.G., Li, J.Q. and Han, X.B. (2014) Analysis of the Heat Generation of Lithium-Ion Battery during Charging and Discharging Considering Different Influencing Factors. Journal of Thermal Analysis and Calorimetry, 116, 1001-1010. https://doi.org/10.1007/s10973-013-3599-9

[5] Martellucci, L. and Giannini, M. (2021) Regenerative Braking Experimental Tests and Results for Formula Student Car. Journal of Transportation Technologies, 11, 78-89. https://doi.org/10.4236/jtts.2021.111005

[6] Naseri, F., Farjah, E. and Ghanbari, T. (2017) An Efficient Regenerative Braking System Based on Battery/Supercapacitor for Electric, Hybrid, and Plug-In Hybrid Electric Vehicles With BLDC Motor. IEEE Transactions on Vehicular Technology, 66, 3724-3739. https://doi.org/10.1109/TVT.2016.2611655

[7] Qiu, C.Q., Wang, G.L., Meng, M.Y. and Shend, Y.J. (2018) A Novel Control Strategy of Regenerative Braking System for Electric Vehicles under Safety Critical Driving Situations. Energy, 149, 329-340. https://doi.org/10.1016/j.energy.2018.02.046 